\title{
APPLICATION OF FORMS AND METHODS OF COMMERCIALIZATION OF INNOVATIONS THROUGH THE INTERACTION OF UNIVERSITIES AND ENTERPRISES
}

\author{
Svetlana E. Sitnikova \\ Volgograd State Medical University, Volgograd, Russian Federation
}

\begin{abstract}
In the conditions of formation of economy based on knowledge, a key condition for successful development is the effective integration of science, education and business. Currently, the commercialization of innovation becomes a necessary factor for sustainable development of universities, one of their main tools to increase its competitiveness in the market of educational services and products. The efficiency of the process of innovation commercialization is conditioned by the rational choice of forms and methods of implementing this process. The interaction of universities and enterprises in the innovative clusters provides benefits such as effective dissemination of information about the creation of innovations, the relevant areas of research, the granting of preferences to cluster participants. The creation of technoparks suggests the presence of a specially allocated site, which houses many new businesses, so that existing institutions can only be partners of the technopark. From the point of view of commercialization of University innovation, the cluster seems to be a more attractive method compared with the creation of technology parks, but its application is necessary to adjust the approach to conducting the state policy in the field of innovation management. The interaction of universities and enterprises via an intermediary - the chamber of commerce and industry - can be described as an obstacle to the commercialization of university innovations. On the contrary, technological innovation center protects the interests of universities, rather than enterprises, as it is created to facilitate the commercialization of university innovation. Direct interaction of universities and enterprises becomes possible with the help of methods of a single transaction, a regular cooperation and a contract for the supply of innovation. The choice of methods of commercialization of innovations should be made on the basis of existing university capabilities, as well as the market situation.
\end{abstract}

Key words: commercialization of university innovations, methods of commercialization of innovations, cluster, technopark, technology innovation center, chamber of commerce and industry.

УДК 378.661:001:33

ББК $72: 65$

\section{СПЕЦИФИКА ПРИМЕНЕНИЯ ФОРМ И МЕТОДОВ КОММЕРЦИАЛИЗАЦИИ ИННОВАЦИЙ ПРИ ВЗАИМОДЕЙСТВИИ ВУЗОВ И ПРЕДПРИЯТИЙ}

\footnotetext{
Светлана Евгеньевна Ситникова

Волгоградский государственный медицинский университет, г. Волгоград, Российская Федерация ного развития является эффективная интеграция науки, образования и бизнеса. В настоящее время коммерциализация инноваций становится необходимым фактором устойчивого развития вузов, одним их основных инструментов повышения его конкурентоспособности на рынке образовательных услуг и продуктов. Эффективность протекания процесса коммерциализации инноваций обусловлена рациональным выбором форм и методов реализации данного процесса. Взаимодействие вузов и предприятий в составе инновационных кластеров обеспечивает такие преимущества, как эффективное распространение информации о созданных инновациях, актуальных направлениях научных исследований, предоставление преференций участникам
} 
кластера. Создание технопарков предполагает наличие выделенной территории, на которой сосредоточено множество новых предприятий, поэтому существующие вузы могут выступать лишь партнерами технопарка. С точки зрения коммерциализации вузовских инноваций кластер выглядит более привлекательным методом по сравнению с созданием технопарков, однако для его применения необходима корректировка подхода к проведению государственной политики в области управления инновациями. Взаимодействие вузов и предприятий через посредника - торгово-промышленную палату можно охарактеризовать как препятствие на пути коммерциализации вузовских инноваций. Напротив, технологический инновационный центр защищает интересы вузов, а не предприятий, так как создается именно в целях содействия коммерциализации вузовских инноваций. Прямое взаимодействие вузов и предприятий становится возможным с помощью методов разовой сделки, регулярного сотрудничества и контракта на поставку инноваций. Выбор представленных методов коммерциализации инноваций целесообразно осуществлять, исходя из имеющихся у вуза возможностей, а также из ситуации на рынке.

Ключевые слова: коммерциализация вузовских инноваций, методы коммерциализации инноваций, кластер, технопарк, технологический инновационный центр, торгово-промышленная палата.

Ключевым фактором успешного функционирования национальной инновационной системы является эффективная коммерциализация вузовских инноваций, в которой вузы играют роль центров по созданию инноваций, а предпринимательство - роль хозяйствующих субъектов, внедряющих эти инновации. Несовершенство системы коммерциализации вузовских инноваций в современной России представляет собой серьезный сдерживающий фактор на пути построения инновационно ориентированной экономики.

Научный подход к сущности процесса коммерциализации вузовских инноваций предполагает его изучение через призму форм и методов.
На основе контент-анализа существующей научной литературы [1-4; 6-8], логического анализа процесса коммерциализации вузовских инноваций и систематизации существующих знаний в данной области нами предлагается следующая классификация форм и методов реализации данного процесса (табл. 1).

Выделенные в таблице 1 формы коммерциализации вузовских инноваций могут сочетаться друг с другом в качестве детализации. Например, при прямом взаимодействии вузов и предприятий может осуществляться продажа инноваций или их сдача в аренду, это могут быть отечественные или иностранные предприятия и т. п. По этой причине одни методы коммерциализации вузов-

Таблица 1

\section{Характеристика процесса коммерциализации вузовских инноваций}

\begin{tabular}{|c|c|c|}
\hline Критерий & $\begin{array}{c}\text { Формы взаимодействия участников } \\
\text { процесса коммерциализации } \\
\text { вузовских инноваций }\end{array}$ & $\begin{array}{c}\text { Сущность взаимодействия участников процесса } \\
\text { коммерциализации вузовских инноваций }\end{array}$ \\
\hline \multirow[t]{3}{*}{$\begin{array}{l}\text { Характер взаимо- } \\
\text { действий вузов и } \\
\text { предприятий }\end{array}$} & Прямое взаимодействие & $\begin{array}{l}\text { Вузы напрямую взаимодействуют с предприятиями и яв- } \\
\text { ляются единственными участниками сделки по коммер- } \\
\text { циализации инноваций }\end{array}$ \\
\hline & Посредничество & $\begin{array}{l}\text { Отношения вуза и бизнеса инициируются и регулируются } \\
\text { посредником }\end{array}$ \\
\hline & Интеграция & Вуз и бизнес входят в состав интеграционного объединения \\
\hline \multirow{2}{*}{$\begin{array}{l}\text { Особенности пе- } \\
\text { рехода права ин- } \\
\text { теллектуальной } \\
\text { собственности на } \\
\text { инновации }\end{array}$} & $\begin{array}{l}\text { Передача права интеллектуаль- } \\
\text { ной собственности на инновации }\end{array}$ & $\begin{array}{l}\text { Вуз утрачивает право интеллектуальной собственности на } \\
\text { инновации в процессе их коммерциализации - они пере- } \\
\text { ходят к бизнесу }\end{array}$ \\
\hline & $\begin{array}{l}\text { Сдача инноваций в аренду при } \\
\text { сохранении права интеллекту- } \\
\text { альной собственности на них }\end{array}$ & $\begin{array}{l}\text { Вуз сохраняет право интеллектуальной собственности на } \\
\text { инновации в процессе их коммерциализации }\end{array}$ \\
\hline \multirow{3}{*}{$\begin{array}{l}\text { Направление сбы- } \\
\text { та вузовских ин- } \\
\text { новаций }\end{array}$} & Только экспорт инноваций & $\begin{array}{l}\text { Вузы проводят сделки по коммерциализации только с } \\
\text { иностранными предприятиями }\end{array}$ \\
\hline & $\begin{array}{l}\text { Сбыт только отечественным } \\
\text { предприятиям }\end{array}$ & $\begin{array}{l}\text { Вузы проводят сделки по коммерциализации только с } \\
\text { отечественными предприятиями }\end{array}$ \\
\hline & $\begin{array}{l}\text { Сочетание экспорта и сбыта оте- } \\
\text { чественным предприятиям }\end{array}$ & $\begin{array}{l}\text { Вузы проводят сделки по коммерциализации и с ино- } \\
\text { странными, и с отечественными предприятиями }\end{array}$ \\
\hline
\end{tabular}

Примечание. Составлено автором. 
ских инноваций могут применяться при различных формах, в то время как другие методы в силу своей специфики соответствуют какой-то конкретной форме.

Рассмотрим формы коммерциализации вузовских инноваций в контексте специфики их применения в современной России (табл. 2).

Одной из таких форм является кластеризация. В составе отраслевого экономического кластера создаются благоприятные условия для коммерциализации инноваций, создаваемых вузами - участниками такого интеграционного объединения. Во-первых, объединение по отраслевой принадлежности обеспечивает потенциальную привлекательность создаваемых вузами инноваций для входящих в кластер предприятий.

Во-вторых, в рамках кластера происходит постоянный обмен информацией. Поэтому о созданных вузами инновациях быстро узнают предприятия, входящие в состав кластера, и, если эти инновации представляют для них интерес, они сформируют спрос. Иными словами, по сравнению с изолированным функционированием объединение вузов и предприятий в отраслевой кластер позволяет повышать осведомленность целевых В2В-потребителей о вузовских инновациях и упрощать для них доступ к этим инноваци- ям в рамках отлаженного внутрикластерного взаимодействия.

Знание потребностей участников кластера в инновациях позволяет вузам проводить научные исследования в востребованных на практике направлениях. Это является весомым преимуществом, так как вузам не приходится осуществлять дополнительные маркетинговые коммуникации, чтобы выявить существующий спрос на инновации. А это значит, что с учетом целевой ориентации вузовских инноваций и быстрого оповещения целевой аудитории о них процесс коммерциализации происходит очень быстро.

В-третьих, в рамках кластера могут действовать специальные условия, обязывающие предприятия внедрять инновации и обусловливающие их привязку к инновациям только вузов, входящих в кластер. К примеру, если кластер имеет статус инновационного, то он получает государственную поддержку (налоговые преференции, финансовые стимулы и т. д.). Для поддержания данного статуса предприятия в составе кластера должны проявлять высокую инновационную активность.

Если предприятия подобраны таким образом, что они не имеют возможности самостоятельно проводить научные исследования

Таблица 2

\section{Классификация форм коммерциализации вузовских инноваций по критерию способа взаимодействия вузов и предприятий}

\begin{tabular}{|c|c|c|}
\hline $\begin{array}{c}\text { Формы } \\
\text { коммерциализации }\end{array}$ & Способ взаимодействия вузов и предприятий & $\begin{array}{c}\text { Характер } \\
\text { взаимодействий }\end{array}$ \\
\hline Кластеры & $\begin{array}{l}\text { Интеграция вузов и предприятий в составе инновационных } \\
\text { кластеров }\end{array}$ & \multirow[t]{2}{*}{ Форма интеграции } \\
\hline Технопарки & Интеграция вузов и предприятий в составе технопарков & \\
\hline $\begin{array}{l}\text { Торгово-промышлен- } \\
\text { ная палата }\end{array}$ & $\begin{array}{l}\text { Взаимодействие вузов и предприятий через посредника - тор- } \\
\text { гово-промышленную палату }\end{array}$ & \multirow[t]{2}{*}{ Форма посредничества } \\
\hline $\begin{array}{l}\text { Технологический ин- } \\
\text { новационный центр }\end{array}$ & $\begin{array}{l}\text { Взаимодействие вузов и предприятий через посредника - тех- } \\
\text { нологический инновационный центр }\end{array}$ & \\
\hline Продажа инноваций & $\begin{array}{l}\text { Взаимодействие вузов и предприятий через продажу вузовских } \\
\text { инноваций предприятиям }\end{array}$ & \multirow[t]{2}{*}{ Форма передачи права } \\
\hline $\begin{array}{l}\text { Исключительная ли- } \\
\text { цензия }\end{array}$ & $\begin{array}{l}\text { Взаимодействие вузов и предприятий через предоставление пред- } \\
\text { приятиям исключительных лицензий на вузовские инновации }\end{array}$ & \\
\hline $\begin{array}{l}\text { Единственная лицен- } \\
\text { зия }\end{array}$ & $\begin{array}{l}\text { Взаимодействие вузов и предприятий через предоставление } \\
\text { предприятиям единственных лицензий на вузовские инновации }\end{array}$ & \multirow[t]{2}{*}{ Форма сдачи в аренду } \\
\hline $\begin{array}{l}\text { Метод неисключи- } \\
\text { тельной лицензии }\end{array}$ & $\begin{array}{l}\text { Взаимодействие вузов и предприятий через предоставление пред- } \\
\text { приятиям неисключительных лицензий на вузовские инновации }\end{array}$ & \\
\hline Метод разовой сделки & Разовое взаимодействие вузов и предприятий & \multirow{3}{*}{$\begin{array}{l}\text { Форма прямого взаи- } \\
\text { модействия }\end{array}$} \\
\hline $\begin{array}{l}\text { Метод регулярного } \\
\text { сотрудничества }\end{array}$ & Регулярное взаимодействие вузов и предприятий & \\
\hline Метод контракта & Взаимодействие вузов и предприятий на условиях контрактов & \\
\hline
\end{tabular}

Примечание. Составлено автором. 
(например, малые инновационные предприятия) или это невыгодно для них, то они будут заведомо предъявлять спрос на вузовские инновации. При этом одним из условий вхождения в состав кластера может являться необходимость сотрудничества только с вузами в рамках кластера, то есть устраняется возможность сотрудничества со сторонними вузами.

В качестве альтернативы вынужденному обращению за инновациями к вузам в составе кластера могут выступать преференции, предоставляемые вузами предприятиям в составе кластера. Это может быть, к примеру, льготная цена на инновации или активное содействие их внедрению в бизнес-процессы. Так обеспечивается более высокая конкурентоспособность инноваций вузов, входящих в состав кластера, по сравнению со сторонними вузами для участвующих в кластере предприятий.

Еще одним преимуществом кластеризации является то, что данная тенденция распространена в современной России. Число кластеров постоянно возрастает. Так, в 2012 г. в России было только 8 отраслевых специализированных кластеров в сфере здравоохранения. По данным на 2017 г., в России насчитывается 16 таких кластеров, то есть прирост составил $200 \%$ за 4 года.

Однако следует заметить, что в 2016 и 2017 гг. не было создано ни одного нового подобного кластера, что свидетельствует о замедлении данной тенденции. Отметим, что неспециализированные кластеры, включающие в себя хозяйствующих субъектов из различных отраслей экономики, исключены нами из выборки, так как они не предоставляют обозначенных преимуществ в области коммерциализации вузовских инноваций.

Несмотря на достаточно большое количество отраслевых специализированных кластеров в сфере здравоохранения, в современной России только 4 из них имеют статус пилотных инновационных территориальных кластеров, а именно:

- Кластер медицинской, фармацевтической промышленности, радиационных технологий Санкт-Петербурга;

- Инновационный территориальный кластер «ФИЗТЕХ XXI» Московской области;
- Инновационный территориальный кластер «Фармацевтика, медицинская техника и информационные технологии Томской области»;

- Алтайский биофармацевтический кластер.

Таким образом, в настоящее время в России насчитывается только 4 кластерных объединения, в которых созданы наиболее благоприятные условия для коммерциализации вузовских инноваций.

Другой формой коммерциализации вузовских инноваций является создание технопарков. Они предполагают наличие выделенной (обособленной) территории, на которой сосредоточено множество новых предприятий в отличие от кластера, который предполагает только организационное, но не территориальное единство и объединяет уже существующие предприятия.

По сравнению с кластером, в который могут войти уже существующие вузы, в рамках технопарка создаются собственные новые научно-исследовательские центры, а уже существующие вузы могут выступать лишь партнерами технопарка после прохождения конкурсного отбора. Это обусловливает ограниченные возможности использования технопарков в интересах коммерциализации вузовских инноваций.

Из 38 российских технопарков, по данным на 2016 г., только 2 специализируются в медицинской сфере - Московский и Новосибирский, причем оба они принадлежат государству и находятся на стадии создания. Это свидетельствует о практической недоступности использования метода технопарка в процессе массовой коммерциализации инноваций современных российских вузов, данный метод является скорее исключением из обычной практики [5, с. 312].

Необходимость наличия выделенной территории предполагает зависимость технопарков от государства. Так как в крупных развитых городах такие территории отсутствуют, поиск места для технопарков является сложной задачей, и даже в случае ее успешного решения технопарк будет расположен за пределами делового центра города, что снижает его привлекательность для деловых партнеров. Это делает технопарк менее доступным 
и менее выгодным методом коммерциализации вузовских инноваций по сравнению с отраслевым инновационным кластером.

В то же время технопарки часто находятся в государственной собственности и потому получают значительное государственное финансирование. Так, если участие в кластерных процессах может обеспечить вузам и предприятиям как максимум маркетинговые выгоды и незначительные государственные преференции как крупного интеграционного объединения, играющего важную роль в экономике территории, то вхождение в технопарк обеспечивает доступ к государственному финансированию научных исследований и предполагает государственный интерес и содействие коммерциализации вузовских инноваций.

Сравнительный анализ кластеров и технопарков произведен в таблице 3.

Как видно из таблицы 3 , представленные формы коммерциализации вузовских инноваций сильно отличаются друг от друга. С точки зрения коммерциализации вузовских инноваций кластер выглядит более привлекательным по сравнению с созданием технопарков, так как предоставляет вузу больше возможностей и преимуществ, а участие в технопарке для вуза ограничено, что лимитирует и потенциальные выгоды, извлекаемые вузом из партнерства с технопарком.

Если говорить о недостатках вовлечения торгово-промышленной палаты в процесс коммерциализации вузовских инноваций, то необходимо отметить тот факт, что коммерциализация вузовских инноваций не является ни целевым, ни даже приоритетным направлением деятельности торгово-промышленной палаты, что определяет посредственное отношение к ней.

Отсутствие требований к содействию коммерциализации вузовских инноваций и нахождение торгово-промышленной палаты в частной собственности (как объединения предпринимателей) устраняет необходимость реализации данной функции. Важно также подчеркнуть, что услуги торгово-промышленной палаты являются платными и в случае ее участия в сделке между вузом и предприятием стоимость инновации возрастает пропорционально прибыли данного посредника.

На основании анализа современного российского опыта торгово-промышленную палату можно скорее охарактеризовать как препятствие на пути коммерциализации вузовских инноваций. К числу немногочисленных преимуществ можно отнести информационную функцию, так как торгово-промышленная палата предоставляет вузам информацию об имеющемся спросе на инновации. Данная информация является полезной изза неразвитости маркетинговой деятельности вузов.

Поэтому если оставить информационное, но устранить организационное посредничество торгово-промышленной палаты в процессе коммерциализации вузовских инноваций в рамках совершения сделки между вузом и пред-

Таблиияа 3

Сравнительный анализ форм обеспечения процесса коммерциализации вузовских инноваций (на примере создания кластеров и технопарков)

\begin{tabular}{|c|c|c|}
\hline \multirow{2}{*}{$\begin{array}{l}\text { Критерии } \\
\text { сравнения }\end{array}$} & \multicolumn{2}{|c|}{ Формы коммерциализации вузовских инноваций } \\
\hline & Кластер & Технопарк \\
\hline $\begin{array}{l}\text { Территориальная обо- } \\
\text { собленность }\end{array}$ & Нет & Да \\
\hline $\begin{array}{l}\text { Географическое распо- } \\
\text { ложение }\end{array}$ & В центрах крупных городов & За пределами крупных городов \\
\hline Предприятия-участники & $\begin{array}{l}\text { Привлечение уже существующих пред- } \\
\text { приятий }\end{array}$ & Создание новых предприятий \\
\hline Участие вуза & Участие в интеграционном объединении & $\begin{array}{l}\text { Партнерство с интеграционным объеди- } \\
\text { нением }\end{array}$ \\
\hline $\begin{array}{l}\text { Преобладающая форма } \\
\text { собственности }\end{array}$ & Частная & Государственная \\
\hline Выгоды для вуза & $\begin{array}{l}\text { Маркетинговые выгоды и незначитель- } \\
\text { ные государственные преференции }\end{array}$ & $\begin{array}{l}\text { Государственное финансирование, содей- } \\
\text { ствие коммерциализации инноваций }\end{array}$ \\
\hline
\end{tabular}

Примечание. Составлено автором. 
приятием, то ее участие может оказаться полезным для участников сделки. Однако в этом случае устраняется коммерческий интерес для самой торгово-промышленной палаты. Как уже отмечалось, это частная организация, и для поддержания своего функционирования она должна получать прибыль.

К одной из форм коммерциализации вузовских инноваций также относится вовлечение технологического инновационного центра в процесс коммерциализации вузовских инноваций. Он также реализуется в виде посредничества, но в отличие от торгово-промышленной палаты технологический инновационный центр защищает интересы вузов, а не предприятий, так как создается именно в целях содействия коммерциализации вузовских инноваций.

Так же как и торгово-промышленная палата, технологический инновационный центр извлекает свою выгоду от посредничества между вузами и предприятиями, что необходимо для покрытия его расходов, ведь он только первоначально создается государством, а впоследствии переходит на самоокупаемость, получая лишь незначительное целевое государственное финансирование. Для технологического инновационного центра неприемлемо вытеснение вуза из процесса коммерциализации инноваций, хотя после совершения сделки технологический инновационный центр может оказывать консульта- ционные услуги бизнесу при внедрении вузовских инноваций.

В отличие от метода торгово-промышленной палаты технологический инновационный центр может осуществлять международную деятельность, тем самым формируя и укрепляя бренд инноваций отечественных вузов и содействуя их экспорту. Хотя, на первый взгляд, может показаться, что это приводит к «утечке» инноваций, представляющих интерес для отечественной экономики, на самом деле это спорный момент.

Бывают случаи, когда создаваемые вузами инновации не востребованы в своей стране, что препятствует их коммерциализации на отечественном рынке. Чтобы обеспечить окупаемость проведенных вузом научных исследований и принести ему прибыль, в этом случае выгодно экспортировать инновации, что невозможно без налаженных международных связей. В то же время содействие экспорту вузовских инноваций вовсе не является одной из основных задач технологического инновационного центра и потому его не стоит рассматривать как недостаток.

Вовлечение торгово-промышленной палаты и технологического инновационного центра применяется в рамках формы посредничества. Проведем их сравнительный анализ с точки зрения коммерциализации вузовских инноваций (табл. 4).

Таблица 4

\section{Сравнительный анализ форм обеспечения процесса коммерциализации вузовских инноваций (на примере торгово-промышленной палаты и технологического инновационногоцентра)}

\begin{tabular}{|l|l|l|}
\hline \multirow{2}{*}{ Критерии сравнения } & \multicolumn{1}{|c|}{ Формы коммерциализации вузовских инноваций } \\
\cline { 2 - 3 } & \multicolumn{1}{|c|}{ Торгово-промышленная палата } & \multicolumn{1}{c|}{$\begin{array}{c}\text { Технологический инновационный } \\
\text { центр }\end{array}$} \\
\hline $\begin{array}{l}\text { Приоритетное отношение к коммер- } \\
\text { циализаци вузовских инноваций }\end{array}$ & Нет & Да \\
\hline $\begin{array}{l}\text { Интерес в посредничестве между ву- } \\
\text { зом и бизнесом }\end{array}$ & $\begin{array}{l}\text { Своя выгода, отстаивание интере- } \\
\text { сов бизнеса }\end{array}$ & $\begin{array}{l}\text { Коммерциализация вузовских ин- } \\
\text { новаций }\end{array}$ \\
\hline Организационная специфика & Объединение предприятий & Независимая организация \\
\hline $\begin{array}{l}\text { Зависимость от государства } \\
\text { Международная деятельность }\end{array}$ & $\begin{array}{l}\text { Минимальная, частная независимая } \\
\text { организация }\end{array}$ & $\begin{array}{l}\text { Только на первоначальном этапе } \\
\text { функционирования }\end{array}$ \\
\hline $\begin{array}{l}\text { Направление запуска процесса ком- } \\
\text { мерциализации вузовских инноваций }\end{array}$ & Спрос со стороны бизнеса & Создание инноваций вузами \\
\hline $\begin{array}{l}\text { Преобладающие объекты сотрудни- } \\
\text { чества }\end{array}$ & Предприятия & Вузы \\
\hline
\end{tabular}

Примечание. Составлено автором. 
Как видно из таблицы 4, по всем критериям технологический инновационный центр превосходит торгово-промышленную палату с точки зрения коммерциализации вузовских инноваций. Единственное, в чем он проигрывает, - это неразвитость технологических инновационных центров в современной России. Региональное представительство торгово-промышленной палаты есть практически в каждом регионе России, что делает данную форму доступной для коммерциализации вузовских инноваций, чего нельзя сказать про технологические инновационные центры, в настоящий момент недоступные в России.

Поэтому для вовлечения технологических инновационных центров необходима корректировка подхода к проведению государственной политики в области управления инновациями. Вместо стимулирования инновационной активности предпринимательства должно производиться содействие коммерциализации вузовских инноваций, чтобы обеспечить целостность инновационного процесса в отечественной хозяйственной системе.

Рассмотрим обобщенный алгоритм реализации разовой сделки по коммерциализации вузовских инноваций. Сначала вуз проводит научные исследования и создает инновацию, а также оформляет (регистрирует) свои права интеллектуальной собственности на нее. Предварительно вузом может быть проведено маркетинговое исследование, направленное на анализ существующих потребностей предпринимательства в инновациях, определение потенциального коммерческого успеха альтернативных инноваций, готовящихся к созданию, и выбор наиболее перспективных с маркетинговой точки зрения таких инноваций.

Однако, как показывает современная российская практика, данный этап часто пропускается отечественными вузами, что является причиной сложностей на последующих этапах коммерциализации вузовских инноваций с помощью данного способа. На следующем этапе вуз проводит различные мероприятия по сбыту готовых инноваций - в этом случае в ход пускаются кластерные механизмы маркетинговых коммуникаций или посредничество, когда вуз обращается к посреднику за помощью.
Рассмотрим изолированное использование разовой сделки по коммерциализации вузовских инноваций. Здесь вуз не может рассчитывать на внешнюю поддержку или специализированные инструменты и полагается только на собственные силы. Он может использовать следующие основные способы продвижения своих инноваций на рынок (в рамках В2В-сотрудничества с предпринимательством):

- реклама: это может быть реклама по телевидению, массовая рассылка на обычную или интернет-почту различных предприятий и т. д.;

- ярмарочно-выставочная деятельность: принимая участие в ярмарках и выставках, вуз может не только проинформировать деловые круги (свою целевую аудиторию) о созданных им инновациях, но и продемонстрировать их в действии на примере прототипов;

- интернет-сайт вуза, на котором можно размещать новости о созданных инновациях.

Затем предприятия, заинтересовавшиеся созданными вузом инновациями, обращаются к нему за более подробной информацией. Если все проходит удачно, заключается сделка по коммерциализации инноваций. Она не предполагает дальнейшее сотрудничество и носит разовый (единовременный) характер, хотя и может предусматривать различные условия перехода или сохранения прав на объекты интеллектуальной собственности.

В случае, если сразу несколько предприятий заинтересовались инновацией, созданной вузом, между ними возникает конкуренция, и вуз может заключить сделку на максимально выгодных для себя условиях. Однако, если никто не заинтересовался созданной вузом инновацией, тот может продолжать попытки информирования о ней целевой аудитории, но коммерциализации при этом не происходит.

В данном алгоритме есть одно очень существенное условие, которое оказывает непосредственное влияние на успех коммерциализации вузовских инноваций. Наличие данного условия определяет отсутствие гарантии успеха процесса коммерциализации, что снижает привлекательность данного метода по сравнению с имеющимися альтернативами. 
Алгоритм осуществления регулярного сотрудничества во многом схож с предыдущим методом за несколькими исключениями. Так, анализ спроса предприятий-партнеров вуза на создаваемые им инновации проводится в рамках метода регулярного сотрудничества обязательно. Это не требует сложных маркетинговых усилий, достаточно проинформировать партнеров о намерениях вуза в области создания инноваций и узнать их мнение. Таких партнеров не так много, и каналы связи с ними отлажены, что значительно упрощает и ускоряет первый этап алгоритма по сравнению с разовой сделкой.

Далее вуз также проводит научные исследования, создает инновации и регистрирует права собственности на них. Затем проводится информирование предприятий-партнеров о созданной инновации через налаженные (проверенные и действующие) каналы коммуникации, что обеспечивает высокую вероятность того, что информация дойдет до адресатов. Затем в случае проявления интереса к инновации заключается сделка по ее коммерциализации.

Условие проявления интереса к инновации по-прежнему сохраняется в рассматриваемом алгоритме коммерциализации вузовских инноваций при использовании метода регулярного сотрудничества. Однако вероятность соблюдения данного условия намного выше, чем в случае применения метода разовой сделки, так как предварительно был проведен анализ спроса на инновации вуза.

Следует отметить и такую форму, как контракт на поставку инноваций. Она значительно отличается от двух предыдущих форм и предполагает использование другого алгоритма коммерциализации вузовских инноваций. На первом этапе происходит инициация инновационного процесса. Его инициатором может выступить сам вуз, обратившись ко всем предприятиям на рынке или к своим предприятиям-партнерам с предложением заключить контракт на поставку инноваций.

Инициатором может выступить и предприятие, обратившись к вузу с запросом на проведение для него научных исследований и создание инноваций. На втором этапе заключается контракт, в котором четко прописываются условия сделки, права и обязанности сторон. На третьем этапе вуз проводит науч- ные исследования, создает инновации и регистрирует права интеллектуальной собственности на них.

На четвертом этапе, согласно условиям контракта, предприятие получает инновацию (с различными вариантами перехода или сохранения за вузом прав интеллектуальной собственности на нее). Данная инновация создана специально для этого предприятия, она готова к практическому применению и представляет интерес и ценность именно для него. При этом она может быть неприменима другими предприятиями. Поэтому в случае расторжения предприятием контракта оно выплачивает штраф в установленном размере, но вуз, скорее всего, уже не сможет найти другого партнера, и коммерциализации инновации не произойдет.

В алгоритме коммерциализации вузовских инноваций с помощью метода контракта также есть условие, которое является причиной опционной коммерциализации инноваций. Однако приложенные вузом усилия и понесенные затраты на проведение научных исследований и создание инноваций окупятся в любом случае, так как его интересы защищены контрактом. С точки зрения вуза этот способ наиболее выгоден, но с точки зрения завершенности инновационного процесса он менее привлекателен по сравнению с разовой сделкой и регулярным сотрудничеством, так как при заключении контракта инновации привязаны к конкретному предприятию и в случае утраты его интереса к ним, к примеру, если его ожидания от научных исследований не оправдались или исчезла необходимость в инновациях, успех их коммерциализации ставится под сомнение.

Рассмотренны еще три формы прямого взаимодействия вузов и предприятий. Результаты их сравнительного анализа с точки зрения коммерциализации вузовских инноваций представлены в таблице 5.

Таким образом, выбор форм и методов коммерциализации инновации целесообразно реализовывать, исходя из имеющихся у вуза возможностей (наличие предприятий-партнеров, готовых к совершению сделки/заключению контракта), а также из ситуации на рынке (оценка вероятности расторжения сделки/ контракта). 


\begin{tabular}{|c|c|c|c|}
\hline \multirow[b]{3}{*}{ Критерии сравнения } & \multicolumn{3}{|c|}{$\begin{array}{l}\text { ествления разовой сделки, } \\
\text { тракта на поставку инноваций } \\
\text { ации вузовских инноваций }\end{array}$} \\
\hline & \multicolumn{3}{|c|}{ Формы коммерциализации вузовских инноваций } \\
\hline & Разовая сделка & Регулярное сотрудничество & $\begin{array}{c}\text { Контракт на поставку } \\
\text { инноваций } \\
\end{array}$ \\
\hline $\begin{array}{l}\text { Величина потенциальной } \\
\text { выгоды вуза }\end{array}$ & $\begin{array}{l}\text { Высокая (неограниченная } \\
\text { целевая аудитория) }\end{array}$ & $\begin{array}{l}\text { Средняя (целевая аудито- } \\
\text { рия ограничена предпри- } \\
\text { ятиями-партнерами) }\end{array}$ & $\begin{array}{l}\text { Низкая (только одно } \\
\text { предприятие-партнер по } \\
\text { контракту) }\end{array}$ \\
\hline Доступность для вузов & $\begin{array}{l}\text { Высокая, предваритель- } \\
\text { ная подготовка не требу- } \\
\text { ется }\end{array}$ & $\begin{array}{l}\text { Средняя, необходимо на- } \\
\text { личие предприятий- } \\
\text { партнеров }\end{array}$ & $\begin{array}{l}\text { Низкая, необходим парт- } \\
\text { нер для заключения кон- } \\
\text { тракта }\end{array}$ \\
\hline Защита интересов вуза & Нет & Нет & Да, контракт \\
\hline $\begin{array}{l}\text { Вероятность коммерциали- } \\
\text { зации вузовских инноваций }\end{array}$ & Низкая & Средняя & Высокая \\
\hline $\begin{array}{l}\text { Вероятность коммерциали- } \\
\text { зации вузовских инноваций в } \\
\text { случае срыва сделки (рас- } \\
\text { торжения контракта) }\end{array}$ & Высокая & Высокая & Низкая \\
\hline
\end{tabular}

Примечание. Составлено автором.

\section{СПИСОК ЛИТЕРАТУРЫ}

1. Кислицина, А. Е. Особенности применения методов и стратегий коммерциализации инноваций в сфере наукоемкого производства / А. Е. Кислицина // Интеграл. -2012. - № 6. - С. 38-39.

2. Косенко, С. Г. Коммерциализация инноваций вуза как фактор его конкурентоспособности / С. Г. Косенко, Е. Н. Новикова // Концепт : науч.метод. электрон. журн. - 2014. - № 5. - С. 26-30.

3. Кудашов, В. И. Формы и методы коммерциализации интеллектуальной собственности / В. И. Кудашов, Ю. В. Нечепуренко // Экономика и управление. -2015 . - № 7. - С. 34-39.

4. Майкова, С. Э. Малые инновационные предприятия как наиболее предпочтительная форма коммерциализации вузовских технологий / С. Э. Майкова, И. А. Головушкин // Интеграция образования. 2013. -№ 4 (73). - C. 31-39.

5. Перечень-список технопарков России 2015-2016. - Электрон. текстовые дан. - Режим доступа: http://russiaindustrialpark.ru/tehnopark catalog_perecheny_spisok_russia. - Загл. с экрана.

6. Фендель, К. А. Методы коммерциализации инноваций / К. А. Фендель // Экономика и предпринимательство. - 2012. - № 3 (26). - С. 311-313.

7. Яковлева, Е. А. Формы и методы совершенствования коммерциализации интеллектуальной собственности в России / Е. А. Яковлева // Научно-технические ведомости Санкт-Петербургского государственного политехнического университета. Экономические науки. - 2013. - № 6-2 (185). C. 50-59.

8. Kolychev, V. D. Conception, technology and methods of development of university system of innovation projects commercialization based on effectuation / V. D. Kolychev, I. V. Prokhorov // Asian Social Science. - 2015. - № 11(8). - C. 44-51.

\section{REFERENCES}

1. Kislitsina A.E. Osobennosti primeneniya metodov i strategiy kommertsializatsii innovatsiy $\mathrm{v}$ sfere naukoemkogo proizvodstva [Application of Methods and Strategies of Innovations Commercialization in the Field of High-Tech Industry]. Integral, 2012, no. 6, pp. 38-39.

2. Kosenko S.G., Novikova E.N. Kommertsializatsiya innovatsiy vuza kak faktor ego konkurentosposobnosti [Commercialization of Innovations as a Factor of Their Competitiveness]. Nauchno-metodicheskiy elektronnyy zhurnal Kontsept, 2014, no. 5, pp. 26-30.

3. Kudashov V.I., Nechepurenko Yu.V. Formy i metody kommertsializatsii intellektualnoy sobstvennosti [Forms and methods of commercialization of intellectual property]. Ekonomika i upravlenie, 2015, no. 7, pp. 34-39.

4. Maykova S.E., Golovushkin I.A. Malye innovatsionnye predpriyatiya kak naibolee predpochtitelnaya forma kommertsializatsii vuzovskikh tekhnologiy [Small Innovative Enterprises as the Most Preferred Form of Commercialization of University Technologies]. Integratsiya obrazovaniya, 2013, no. 4 (73), pp. 31-39.

5. Perechen-spisok tekhnoparkov Rossii 2015-2016 [The List of Technoparks of Russia 20152016]. URL: http://russiaindustrialpark.ru/tehnopark_ catalog_perecheny_spisok_russia. 
C.E. Ситникова. Специфика применения форм и методов коммерциализации инноваций

6. Fendel K.A. Metody kommertsializatsii innovatsiy [Methods of Innovations Commercialization] Ekonomika i predprinimatelstvo, 2012, no. 3(26), pp. 311-313.

7. Yakovleva E.A. Formy i metody sovershenstvovaniya kommertsializatsii intellektualnoy sobstvennosti v Rossii [Forms and Methods to Improve the Commercialization of Intellectual Property in Russia].
Nauchno-tekhnicheskie vedomosti SanktPeterburgskogo gosudarstvennogo politekhnicheskogo universiteta. Ekonomicheskie nauki, 2013, no. 6-2 (185), pp. 50-59.

8. Kolychev V.D. Conception, technology and methods of development of university system of innovation projects commercialization based on effectuation. Asian Social Science, 2015, no. 11 (8), pp. 44-51.

\section{Information about the Author}

Svetlana E. Sitnikova, Senior Lecturer, Department of Economics and Management, Volgograd State Medical University, Pavshikh Bortsov Sq., 1, 400031 Volgograd, Russian Federation, ses1113@yandex.ru.

\section{Информация об авторе}

Светлана Евгеньевна Ситникова, старший преподаватель кафедры экономики и менеджмента, Волгоградский государственный медицинский университет, пл. Павших Борцов, 1, 400131 г. Волгоград, Российская Федерация, ses1113@yandex.ru. 